\title{
Erratum to: On the "Virtue Turn" and the Problem of Categorizing Chinese Thought
}

\author{
Eric L. Hutton ${ }^{1}$
}

Published online: 14 September 2015

(C) Springer Science+Business Media Dordrecht 2015

\section{Erratum to: Dao (2015) 14:331-353 \\ DOI 10.1007/s11712-015-9445-y}

The published online paper unfortunately contained errors. The internal references found in footnotes 4 and 57 should be corrected as follows:

\footnotetext{
${ }^{4}$ To some, this point might seem so obvious as not to need argument, but given the criticisms of virtue ethical readings of Chinese texts that appear in various places (see below pp. 337-340 and footnote 22, p. 339), I think the argument is nonetheless worth making.

${ }^{57}$ As before (p. 342), a number of virtue ethical interpreters have been fairly modest and focused in their discussion of the issues, carefully delineating the scope of their interpretive claims, so no blanket condemnation is intended here. On the other hand, I think that for those steeped in the virtue ethics literature (myself included), there remains a hazard of losing sight of how their discussions can seem to others who are not steeped in that literature and do not appreciate its complexities. Of course, the critics have responsibility not to misread the virtue ethical interpreters of Chinese thought, but the interpreters can and should also take steps to try to forestall misunderstandings.
}

Further, the internal reference found in the fifth line of the third paragraph on p. 342 should be corrected from "p. 368 " to "p. 346."

The online version of the original article can be found at http://dx.doi.org/10.1007/s11712-015-9445-y.

Eric L. Hutton

eric.hutton@utah.edu

1 Department of Philosophy, University of Utah, 215 S. Central Campus Dr., CTIHB 402, Salt Lake City, UT 84112, USA 